\title{
CORRESPONDENCE
}

\section{Research Reorganization}

SiR,-I would like to refer to your editorial entitled "Keeping a Straight Bat" (Nature, 231, 2; 1971) in which you refer to the various courses of action which are open to Mrs Thatcher, Minister for Education and Science, with respect to the support of research. You say, "Thus it may be possible enormously to increase the amount of research carried on within the academic section by lumping together those activities of the research councils - the MRC and the ARC as well as the Science Research Council-which are concerned with basic research". You go on to say that "specifically it should be possible to earn great benefits by incorporating many of the basic research units and stations maintained by the MRC and the ARC within universities and polytechnics". The idea of a close association between the research institutes and the universities is certainly not new and there has probably been as much movement in this direction in recent years as is possible when we realize that new buildings are often involved.

It is, however, a later remark in the editorial which I find much more disturbing: "But would not the merging of the research councils create too monolithic a central sponsor ?"... "The case for welding them together into a more efficient (because larger) organization for supporting academic research is, first, that the funds available for such work will fall short of real need in the years ahead and that a properly organized and more powerful research council would be able to make more rational decisions about priorities in research."

We have heard many different ideas about the reorganization of the research councils in recent months, ideas which if acted upon would have a profound effect on the organization of research in this country. I am sure that this feeling of uncertainty has already done much harm to the efficient working of the councils. The scientists themselves feel as if they were being buffeted in a storm not knowing from which direction the wind will blow next. The idea of a monolithic research council really seems the most stupid of all the current ideas. It is easy to predict that no sooner had it been set up than it would be necessary to sectionalize it along the lines of the present research councils. The idea that size necessarily brings efficiency is extremely naive. The Council for Scientific Policy should be capable of making rational decisions about priorities in research.

$$
\begin{aligned}
& \text { Yours faithfully, } \\
& \text { P. N. CAMPBELL }
\end{aligned}
$$

Department of Biochemistry,

9 Hyde Terrace,

Leeds LS2 $9 L S$

\section{Kidney Transplants}

SIR,-Your leading article "Nothing Much to Report on Transplants" (Nature, 231,274 ; 1971) drew attention to the need for centres to coordinate the matching and distribution of cadaver kidneys so that patients needing renal transplants may receive as closely matched kidneys as possible. Your readers were given the impression that nothing is being done about this in Britain. In fact two centres have been working actively for the past two years, one in Newcastle and the other in London. Each provides a 24 hour service with a medically qualified immunologist backed up by a computerized register of recipient information. Each centre coordinates the typing and distribution of cadaveric kidneys to and from a group of collaborating hospitals. The centres in Newcastle and London work closely and amicably together and with the comparable organizations on the continent-Eurotransplant, Scandia-transplant and France-transplant.

The London Transplant Group began in 1968 as a collaboration between three hospitals: in 1970 there were 15: today there are 22. At first the pool of patients awaiting transplant was only 30 : in 1970 it had risen to 170: today it stands at 400 . By June 1970 the LTG had arranged 85 transplants: a year later this number had risen to 220 .

By increasing the size of the recipient pool, it has been possible to improve the tissue matching. In 1969 less than one in ten transplants had as many as three of their four HL-A antigens in common. In the first 6 months of 1971 , no less than $61 \%$ of all transplants arranged by the LTG had three or four HL-A antigens in common, whilst in sixteen transplants all four antigens were identical, a closeness of matching not yet approached by any similar organization in Europe or America.

The improvement in matching has been reflected in the survival of kidneys after transplantation. If we exclude the kidneys which never survive the grafting operation, we find that 9 months later all those with $4 / 4$ antigens in common are still functioning and $88 \%$ of those with $3 / 4$ matches, whereas only $67 \%$ and $57 \%$ of those in two less well matched categories are still surviving. The differences between the best ( $3 / 4$ and $4 / 4)$ and worst matches are highly significant.

We are not surprised that your leading article made no reference to either the Newcastle or the London centres. Neither of them gets any official approval or financial support from the Department of Health and Social Security. Quite the reverse: far from supporting either enterprise, the Department has recently decided to set up an entirely new centre at Bristol and destroy the existing organizations. The new centre, for which an expensive computer has been allocated, is to concern itself only with the British Isles. This is the reverse of progress. On the one hand we are likely to face a prolonged interregnum during which our patients will be deprived of well matched kidneys, since the necessary experience and know-how to run such a coordinating centre does not spring up overnight.

On the other hand, the cooperation with Europe and Eire which has been built up so laboriously, and which has already borne such fruit, is to be deliberately terminated. What is required now is not a new National Centre: like the existing regional network, it must surely be superseded by a European one. This should be the real object of the Department and, until it can achieve it, it would be grossly wasteful not to support existing centres in Newcastle and London.

\section{Yours faithfully, \\ J. P. BLANDY \\ H. FESTENSTEIN}

The London Hospital,

Whitechapel,

London $E 11 B B$

\section{Scientologists}

SiR,- I could scarcely believe my eyes when I read your Washington Correspondent's report on the US Food and Drug Administration's battle with the scientologists (Nature, 231, 485; 1971). The extreme vigour with which the FDA carried out its campaign against Wilhelm Reich might well be thought overdone, 
though no one could seriously suggest (as your correspondent seems to allow) that sales of the orgone box could have continued.

It may just be that the scientologists are unjustly persecuted but all the evidence available suggests that they are a thousand times more dangerous to those who fall into their clutches than poor Reich ever was. The laughable scientific background to scientology does not prevent its being taken very seriously by some people.

It is foolish to say "the FDA alleges that the E-meters are a medical device". The scientologists themselves make claims tantamount to this. They may call themselves a church but your correspondent appears to be the first person to be taken in by this style.

Yours faithfully,

CHRISTOPHER MACY

General Editor,

Rationalist Press Association Ltd, 88 Islington High Street,

London N1 8EW

\section{Obituary}

\section{Professor I. E. Tamm}

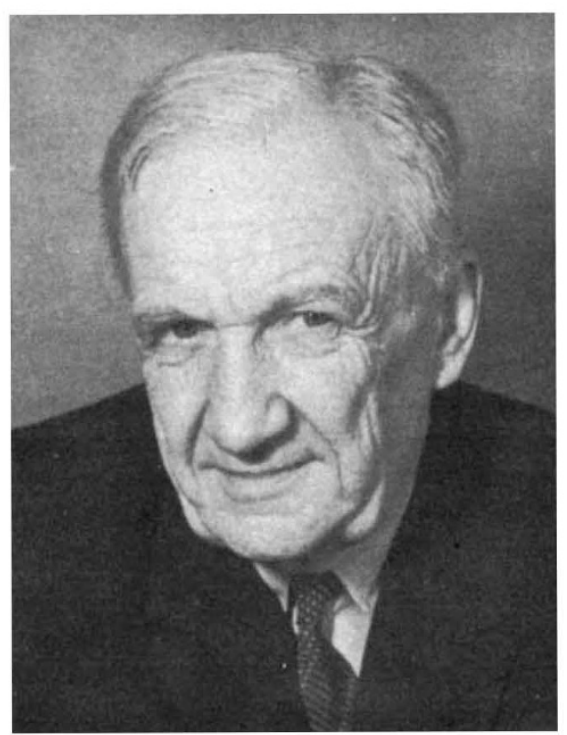

Igor Evgen'evich TAMM, who died on April 12, was one of the Soviet Union's most distinguished and best loved physicists. Born in 1895, the son of a civil engineer, he studied at Edinburgh from 1913, but at the outbreak of the First World War returned to Moscow University, where he graduated in 1918. At that time theoretical physics was not a highly developed subject in the Russian universities. Making this point in a biography of Ya. I. Frenkel, Tamm recalls that Maxwell's theory was deemed to be too complicated to be treated in lectures. "To be sure it was taught in a special 'elective' course by A. Bachinskii, but I was given a top grade in the examination on that course only because in deriving formulae on the blackboard I used the symbol for the vector product and knew its meaning; no other questions were asked of me at all."

This did not stop Tamm from getting thoroughly immersed in the subject, but at the outbreak of the Civil War academic life became very difficult, especially because he was teaching at this time in the University of the Crimea, a region particularly affected by the turmoil of the Civil War. The company of Frenkel, however, another young theoretical physicist with similar interests, was most valuable. 1921-22 was spent at the Odessa Polytechnic under L. I. Mandelstam, an outstanding physicist. This was the beginning of a lifelong close association.

In 1922 Tamm returned to Moscow University, where he became a professor in 1930. Later he joined the new Lebedev Institute of the Academy of Sciences, while remaining, most of the time, parttime professor at the university. His earliest research work was in the field of electrodynamics and relativity. When the new quantum mechanics developed in the late nineteen-twenties, Tamm picked up the new ideas with enthusiasm. He was one of the first to apply quantum mechanics to the scattering of light by solids, and thus to explain the discovery by Mandelstam and Landsberg of a doublet of lines in the scattered light. In another important piece of work on solids he showed the existence of surface states for electrons in metals.

When in 1934, Cherenkov, a research student in the same institute, noticed a strange radiation accompanying the passage of fast electrons through a transparent substance, Tamm saw at once that this was predicted by Maxwell's equations if the speed of the particles exceeded that of light in the medium. He worked out the full theory of this effect with I. M. Frank, and in 1958 shared the Nobel Prize with Frank and Cherenkov.

As time went on, his interest shifted more and more towards the fundamental problems in physics. He attempted to build a theory of nuclear forces on the phenomenon of $\beta$ decay, but recognized that the resulting force would be much too weak. While this work therefore did not directly yield useful results, it aroused his interest in the treatment of interacting fields, and he later proposed a technique for approaching the theory of such problems which, under the name of "TammDancoff method", is still one of the important tools of the theoretical physicist. Numerous other papers dealt with more specific problems in the theory or with the interpretation of experiments.

During the war and post-war years he, like most other scientists, contributed to the solution of urgent practical problems.
Rumour says that he contributed to the development of the fusion bomb in the Soviet Union; he certainly did important work on the problem of power from fusion.

But his influence on physics transcends the list of specific achievements. He was a most stimulating influence in discussion, because of his clarity of mind, his speed in seeing the point and, above all, his infectious enthusiasm. He was a person of fearless integrity, direct and simple in manner, and of extreme modesty. From 1953 he was a full member of the Soviet Academy of Sciences, and thus in a position which confers such a high status and so many privileges that an average person may well be excused for taking himself a little seriously as a result. But for Tamm to display his own importance would have been quite unthinkable.

He was an enthusiastic supporter of the Pugwash conferences, of which he attended several, including the one in London in 1962, where he put forward the idea of "black boxes" to verify a nuclear test ban treaty. While this idea was not ultimately accepted in international negotiations, it helped to create a more constructive spirit and played its part in bringing about at least a partial test ban.

Tamm was a passionate mountaineer, of professional standard, and he spent much of his vacation time in the mountains until a few years ago. During his last illness, which kept him confined to bed with a breathing machine, he was not given to complaining, in spite of much discomfort, and he continued working on some new ideas, but he did admit his regret that this kept him from the mountains. He will be remembered not only as one of the most distinguished but also one of the most charming persons in the world of physics.

\section{Errata}

IN the article "Late Pre-Cambrian Glaciation in Australia as a Stratigraphic Boundary" by P. R. Dunn, B. P. Thomson and Kalervo Rankama (Nature, 231, $498 ; 1971)$, the sentence starting on line 21 beneath the subheading Sturtian Glaciation as Boundary should read: "The base of the proposed unit is to be marked by a reference point, called the Sturt Marker (Marker Horizon), provisionally placed in South Australia at the base of the granite conglomerate which forms the bottom member of the Fitton Formation ${ }^{33}$."

IN the article "Preliminary Observations on Tickling Oneself" by L. Weiskrantz, J. Elliott and C. Darlington (Nature, 230, $598 ; 1971)$, the words "a selfadministered" on line 17 of paragraph 6 should read "an externally administered". 